\title{
Título da página eletrónica: Instituto Promundo
}

URL: http://www.promundo.org.br/

Tatiana Moura, Júlia Garraio e Sílvia Roque

\section{CpenEdition}

\section{Journals}

Edição electrónica

URL: http://journals.openedition.org/rccs/4882

DOI: $10.4000 /$ rccs. 4882

ISSN: 2182-7435

\section{Editora}

Centro de Estudos Sociais da Universidade de Coimbra

Edição impressa

Data de publição: 1 março 2012

Paginação: 203-204

ISSN: 0254-1106

Refêrencia eletrónica

Tatiana Moura, Júlia Garraio e Sílvia Roque, «Título da página eletrónica: Instituto Promundo », Revista Crítica de Ciências Sociais [Online], 96 | 2012, posto online no dia 15 fevereiro 2013, consultado o 22 setembro 2020. URL : http://journals.openedition.org/rccs/4882 ; DOI : https://doi.org/10.4000/rccs 4882 


\section{Espaço Virtual}

\section{Título da página eletrónica: Instituto Promundo URL: http://www.promundo.org.br/}

O Instituto Promundo é uma organização não-governamental brasileira que atua no Brasil e internacionalmente - com escritórios no Rio de Janeiro (Brasil), em Washington, DC (Estados Unidos) e em Kigali (Ruanda) - para promover masculinidades não-violentas e relações de género equitativas. O Promundo define-se como um instituto de pesquisa aplicada que leva a cabo programas de intervenção, testando e avaliando metodologias próprias, e que realiza ações de advocacy para políticas e programas em contextos de violência urbana, pós-conflito e guerra.

A organização atua em torno de cinco grandes áreas programáticas: 1) transformação de normas de género; 2) promoção de masculinidades não-violentas em contextos de pós-conflito e alta violência urbana; 3) envolvimento de homens na paternidade e nos cuidados infantis; 4) transformação de masculinidades para a redução da pobreza e empoderamento económico de mulheres; 5 ) transformação de masculinidades para a prevenção de violência e exploração sexual.

$\mathrm{O}$ site permite conhecer a missão e o trabalho desta instituição, que é reconhecida por organismos internacionais como a UNICEF, a UNFPA, o PNUD, entre outros, por desenvolver, junto a instituições parceiras (Instituto Papai, ECOS e Salud y Genero), o Programa H (de homem), uma metodologia inovadora que visa estimular a reflexão e o envolvimento de homens em ações de promoção da equidade de género. Nos últimos dez anos, o Promundo implementou o Programa H, bem como o Programa M (voltado para o envolvimento de mulheres na equidade de género) em diversos contextos - América Latina, Europa, Ásia e África e tem sido capaz de medir mudanças positivas de atitudes e comportamentos relacionados com violência de género, saúde sexual e reprodutiva e atitudes que se relacionam com violência sexual.

Desde 2009, o Promundo coordenou, em parceria com o International Center for Research on Women (ICRW), o Projeto "Men and Gender Equality Policy" (MGEPP), uma iniciativa de pesquisa e advocacy de longo prazo, que envolveu vários países. O estudo IMAGES (International Men and Gender Equality Survey) já foi realizado na Bósnia e Herzegovina, Brasil, Chile, Croácia, República Democrática do Congo, Índia, Malaui, Mali, México, Ruanda e África do Sul. O projeto pretendeu produzir conhecimento de base para o desenho de novas metodologias, programas de ação e políticas públicas de fomento da equidade de género. $\mathrm{Na}$ secção do site dedicada ao projeto é possível ter acesso a todos os relatórios e publicações realizados pelo Promundo e outras instituições em diferentes países.

Recentemente, a instituição tem ampliado o seu campo de atuação, dedicando-se à realização de pesquisas e de programas de ação em contextos de guerra e pós-guerra. Exemplos disso são os projetos de empoderamento económico das mulheres no Ruanda ou o estudo IMAGES realizado na República Democrática do Congo, que revelou que mais de um terço dos homens entrevistados já tinha praticado alguma forma de violência sexual e que 
mais de três quartos do total dos entrevistados demonstravam atitudes alarmantes face aos direitos das mulheres e em particular face às situações de violação. O relatório confirmou que a violência sexual, usada muitas vezes enquanto arma de guerra, reflete mais frequentemente a aceitação generalizada de normas patriarcais e de mitos que justificam e naturalizam a violação, a subordinação quotidiana das mulheres e o sentimento de propriedade dos homens em relação aos corpos das mulheres. Os resultados também confirmam a gravidade com que o conflito na República Democrática do Congo afeta as famílias: três quartos dos homens e mulheres entrevistados tiveram de abandonar as suas casas devido ao conflito.

Este estudo pode ser lido na íntegra na secção "Publicações" do site. Esta secção disponibiliza uma gama de relatórios completos com resultados de outras pesquisas, monitoramento do impacto das intervenções realizadas pelo Promundo em diferentes contextos, além de guias e manuais educativos para a disseminação das metodologias desenvolvidas ao longo de 15 anos em escolas, creches, serviços de saúde e comunidades. Muitos documentos estão disponibilizados em língua inglesa e portuguesa, mas também em espanhol e francês.

Através da Loja Virtual é possível adquirir produtos e materiais educativos produzidos pela instituição, como os Manuais $\mathrm{H}$ e M e os vídeos "Minha vida João", "Era uma vez outra Maria", "Medo de quê?" e "Era uma vez outra família". Trata-se de desenhos animados que visam questionar normas tradicionais de género e sensibilizar para temas como primeiros relacionamentos sexuais, violência, uso de drogas, gravidez na adolescência, diversidade sexual e prevenção de castigos físicos e humilhantes contra crianças e adolescentes. Por não serem falados, são de fácil utilização em diferentes contextos e países.

Os interessados em receber o boletim eletrónico trimestral (versões em inglês e português) com atualizações sobre as atividades e sobre novas publicações do Promundo podem registar-se no site.

\section{Título da página eletrónica: SVAC - International Research Group "Sexual Violence in Armed Conflict" URL: http://www.warandgender.net/}

A rede internacional Sexual Violence in Armed Conflict (SVAC), criada oficialmente em 2010, reúne um conjunto de investigadoras de diversas áreas científicas (historiadores/as, sociólogos/as, juristas, filósofos/as, psicólogos/as, especialistas das área da literatura e dos estudos culturais, etc.) e de ativistas dos direitos humanos que trabalham sobre questões relacionadas com a violência sexual em conflitos armados. O projeto inicial partiu das investigadoras do Hamburger Institut für Sozialforschung (Alemanha), Gaby Zipfel e Regina Mühlhäuser, que preten- diam promover a discussão entre peritos na matéria numa perspetiva interdisciplinar. Realizou-se até ao momento uma série de encontros e workshops, que decorreram em Hamburgo, Londres, Coimbra e Paris, e estão planeadas atividades futuras e uma maior colaboração entre as instituições dos membros da rede (Alemanha, França, Reino Unido, Estados Unidos, África do Sul, Coreia do Sul, Brasil). O objetivo é a criação de um espaço de reflexão e diálogo entre estudos empíricos e teóricos, onde os/as investigadores/as e os/as ativistas possam discutir os seus trabalhos, 
comparar estudos de caso provenientes de diferentes teatros de guerra e de conflito, a partir de abordagens teóricas multifacetadas. As publicações individuais dos membros da rede oferecem um vasto leque de bibliografia sobre o tema: vão desde relatórios para ONGs, a trabalhos científicos na área da História, Antropologia, Sociologia, Estudos Culturais, Direito, Filosofia, Literatura, incidindo sobre palcos de guerra tão distintos como a Segunda Guerra Mundial, a Argélia, a desintegração da Ex-Jugoslávia, a África do Sul, a Chechénia, o Sri Lanka ou a "guerra ao terrorismo".

\section{Título da página eletrónica: Sexual Violence in Armed Conflicts, 1989-2009 (SVAC) URL: http://www.prio.no/Projects/Project/?x=932}

"Sexual violence in armed conflicts" (SVAC) é um projeto de investigação dirigido por Inger Skjelsbæk no conceituado Instituto de Estudos para a Paz de Oslo (PRIO). Num contexto internacional em que a violência sexual em conflitos armados tem recebido considerável atenção mediática e se tem assistido a algumas tentativas com vista a levar os responsáveis a julgamento e a promover medidas preventivas, este projeto parte do princípio de que, para se lidar com o problema eficazmente, é necessário dispor de conhecimento profundo e sistemático das variações na ocorrência da violência sexual, enquanto conceito que não se limita à violação. Pretende assim oferecer um mapeamento das formas e dos níveis de violência sexual através da análise de um largo espectro de países devastados pela guerra, focando tanto os executores como as vítimas com o objetivo de compreender porquê, quando e onde ocorre a violência (e também quando e porque não ocorre). O objetivo é a criação de uma base de dados da violência sexual em guerras civis entre 1989 e 2009. Entre as publicações já surgidas no âmbito do projeto destaca-se Sexual Violence in African Conflicts, de Nordås Ragnhild (2011, PRIO). O projeto SVAC faz parte da vasta investigação desenvolvida no PRIO de análise de conflitos armados, formulação e documentação de abordagens analíticas e respostas a situações de guerra. A consulta da lista de projetos já finalizados e em curso neste Instituto dá acesso a uma vasta investigação e a contactos de investigadores da área dos Estudos para a Paz que trabalham atualmente sobre a situação das mulheres em zonas de conflito armado.

\section{Título da página eletrónica: Observatorio de la Violencia de Género contra la Mujer URL: http://observatoriodeviolencia.ormusa.org/index.php}

O Observatorio de la Violencia de Género contra la Mujer é da responsabilidade da Organização de Mulheres Salvadorenhas (ORMUSA), uma ONG feminista que trabalha, formalmente desde 1985, em prol da igualdade e justiça entre os sexos no país.
Dedica-se à sistematização e divulgação de dados sobre vários tipos de violência contra as mulheres em El Salvador (feminicídios, violência sexual, intrafamiliar e social), baseando-se nos relatórios da polícia, do instituto de medicina legal e 
na observação dos meios de comunicação social, assim como na investigação sobre políticas públicas. Promove também a formulação de propostas de estratégias de prevenção da violência contra as mulheres. É um espaço constantemente atualizado, com indicadores detalhados e relativos a vários anos, que facilita o trabalho de investigação, quer académica, quer ativista. Têm várias publicações entre as quais resumos informativos dos dados recolhidos cada dois ou três meses, ou ainda análises mais abrangentes sobre temas específicos. 